\title{
Modelo numérico tri-dimensional linear da plataforma continental do Estado do Maranhão
}

\author{
José Edson Rodrigues PEREIRA \& Joseph HARARI \\ Instituto Oceanográfico da Universidade de São Paulo \\ (Caixa Postal 66149, 05389-970, São Paulo, SP, Brasil)
}

\begin{abstract}
- Abstract: A linear three-dimensional hydrodynamical numerical model, Heaps type, was implemented to the continental shelf of Maranhão State, aiming the simulation of the circulation generated by astronomical and meteorological effects in that area. Five runs of the model were performed, in order to compute the circulation in the shelf due to the following effects: principal lunar semi-diurnal component $\left(\mathbf{M}_{2}\right)$, composition of the principal astronomical components in the area, mean summer meteorological conditions, mean winter meteorological conditions and tidal forcing in specific periods of interest. $\mathrm{M}_{2}$ cotidal maps and currents ellipses were obtained, that one being the most important component in the tidal circulation. Mean seasonal elevations and currents are generally much smaller than the astronomical ones, allowing the use of tidal forcing only in hydrodynamic predictions.The model simulations were satisfactory in the platform and less precise within bays and internal shallow areas, where significative delays are observed, due to effects of smaller scale than the one adopted by the model.
\end{abstract}

- Resumo: Um modelo numérico hidrodinâmico tri-dimensional linear, do tipo Heaps, foi implementado para a plataforma continental do Estado do Maranhāo, visando a simulação da circulação gerada por efeitos astronômicos e meteprológicos na área. O modelo foi processado para cinco condiçōes, a fim de calcular a circulação na plataforma devida aos seguintes efeitos: componente de maré semi-diurna lunar principal $\left(\mathrm{M}_{2}\right)$, composição das principais componentes astronômicas de maré na área, condiçōes meteorológicas médias de verāo, condiçōes meteorológicas médias de inverno e forçantes de maré em períodos específicos de interesse. Mapas cotidais e elipses de correntes da componente $\mathrm{M}_{2}$ foram obtidos, sendo esta componente preponderante na circulação local. Elevaçôes e correntes sazonais médias são, em geral, muito menores que as astronômicas, permitindo o uso apenas de forçantes de maré em previsōes hidrodinâmicas. As simulaçōes do modelo foram satisfatórias na plataforma e menos precisas nas baías e áreas internas rasas, onde atrasos de fase significativos sẫo observados, devido a efeitos de menor escala que a adotada pelo modelo.

- Descriptors: Numerical modelling, Three-dimensional linear models, Tidal currents, Drift currents, Cotidal maps, Mean seasonal circulations, Dissipative coefficients, Continental shelf of Maranhẩo State, Brazil.

- Descritores: Modelagem numérica, Modelos tri-dimensionais lineares, Correntes de maré, Correntes de deriva, Mapas cotidais, Circulaçōes sazonais médias, Coeficientes dissipativos, Plataforma Continental do Estado do Maranhão, Brasil.

\section{Introdução}

Desde o tempo de Newton, matemáticos e físicos, como Bernoulli, Laplace, Darwin, Poincaré e outros, têm estudado o problema da maré. Mas, apesar dos

Contr. $\mathrm{n}^{\circ} 774$ do Inst. oceanogr. da Usp. importantes resultados que surgiram do estudo deste fenômeno, a solução analítica da circulação oceânica gerada pela maré é conhecida apenas para um oceano de geometria relativamente simples.

Com o desenvolvimento de computadores progressivamente mais eficientes, tornou-se possível a obtençāo de soluçōes numéricas para as equaçōes 
representativas da circulação de maré, como as equaçōes de águas rasas (Defant, 1961). Posteriormente, soluçōes para o sistema completo de equaçōes foram desenvolvidas, como em Schwiderski (1980).

Além das simulaçōes de maré astronômica, a modelagem numérica hidrodinâmica tem sido extensivamente utilizada para a simulação de correntes geradas por efeitos meteorológicos - essencialmente a friç̧āo do vento e os gradientes de pressāo atmosférica (Ramming \& Kowalik, 1980). Neste caso, além da imposiçāo de condiçōes de contorno oceanográficas nos limites abertos, há a necessidade de especificar condições de contorno na superfície.

O modelo numérico utilizado no presente trabalho fundamenta-se em Heaps (1972), cuja soluçāo numérica desenvolvida para a circulaçāo em áreas costeiras é baseada nas equaçōes hidrodinâmicas linearizadas, sob a aproximação de águas rasas, integradas na vertical e resolvidas através do método de Galerkin, o que possibilita recuperar os perfis verticais de corrente (Davies \& Stephens, 1983). Este método resultou em um modelo numérico hidrodinâmico tridimensional linear, para aplicaçōes em meso-escala (Harari, 1984; 1985).

A área modelada no presente trabalho, sobre a Plataforma Nordeste do Brasil, no Estado do Maranhão, é limitada na linha da costa pela Barra das Preguiças (MA) e pela Baía de Turiaçu (MA); o limite aberto se encontra aproximadamente na isóbata de $100 \mathrm{~m}$ (Fig. 1).

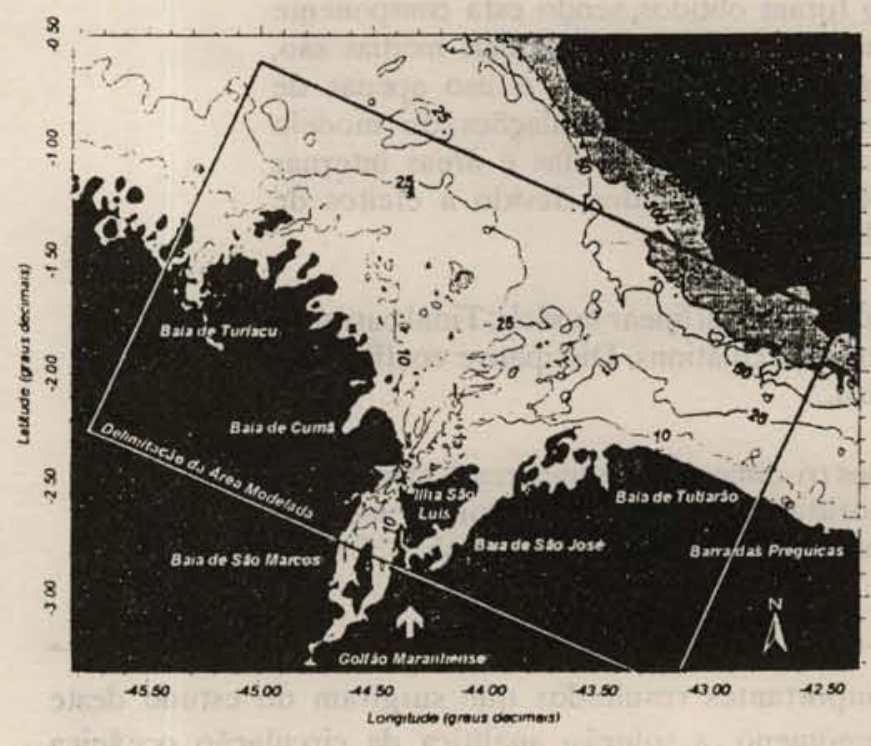

Fig. 1. Mapa da região em estudo e nomes dos acidentes geográficos.
De litoral bastante recortado, com a presença de bancos de areia nos meandros da costa, a região caracteriza-se, hidrodinamicamente, pela presença de fortes correntes, principalmente devido à maré, e climaticamente, por ocorrer duas estações durante o ano (chuvosa de abril a julho e seca de outubro a janeiro), estando sob atuação dos ventos alíseos (Ferraz, 1975).

A motivação prática do desenvolvimento deste trabalho vincula-se ao fato desta área ser relativamente pouco estudada, se considerada sua grande importância econômica para o país, com portos e indústrias ligados à exploração e exportação de minérios.

De um ponto de vista científico, há também o interesse pelas características da maré local, a qual chega a atingir em algumas regiōes alturas máximas de $7 \mathrm{~m}$, uma das maiores do Brasil, com intensas correntes de maré, atingindo valores da ordem de $2 \mathrm{~m} / \mathrm{s}$.

Assim sendo, a adaptação e implementação deste modelo na regiâo têm como objetivos: a reprodução da circulação gerada pela maré e por efeitos meteorológicos na área; o estudo de características dessas circulaçōes; e finalmente, a verificaçāo da possibilidade de utilizaçāo desta modelagem na previsão do nível do mar e das correntes na regiâo (Pereira, 1993).

\section{Material e métodos}

\section{Formulação matemática do modelo}

A partir do sistema geral de equaçōes hidrodinâmicas, é derivado um sistema barotrópico simplificado, com métrica cartesiana no plano $\beta$ equatorial, que descreve as componentes de corrente u, v e w e o nível do mar $\eta$ em função das variáveis independentes representativas do espaço $x, y, z$ e do tempo $t$.

Nestas condiçōes, reescrevendo o sistema de equaçōes, já considerando a aproximação de águas rasas, com a incorporaçāo da relaçāo hidrostática nas equaçōes, sendo a densidade $\rho$ constante, ignorando as tensōes de cisalhamento horizontais e a advecção, aproximando o parâmetro de Coriolis como $\mathrm{f}=\beta \mathrm{y}$ e com a integraçāo na vertical da equação da continuidade, resultam as Equações 1 a 3. Nessas equaçōes, $g$ representa a aceleração da gravidade, h a profundidade média, $\mathrm{P}_{\mathrm{a}}$ a pressāo atmosférica na superfície e $\mathrm{N}$ corresponde ao coeficiente de viscosidade turbulenta vertical.

$$
\frac{\partial \eta}{\partial t}+\frac{\partial}{\partial x} \int_{0}^{h} u d z+\frac{\partial}{\partial y} \int_{0}^{n} v d z=0
$$

$$
\frac{\partial u}{\partial t}-f v=-g \frac{\partial \eta}{\partial x}-\frac{1}{\rho} \frac{\partial P_{g}}{\partial x}+\frac{\partial}{\partial z}\left(N \frac{\partial u}{\partial z}\right)
$$




$$
\frac{\partial v}{\partial t}+f u=-g \frac{\partial \eta}{\partial y}-\frac{1}{\rho} \frac{\partial P_{s}}{\partial y}+\frac{\partial}{\partial z}\left(N \frac{\partial v}{\partial z}\right)
$$

Partindo de uma análise de escala dos termos desconsiderados nas equaçōes hidrodinâmicas, considerando valores típicos em meso-escala para estas variáveis, observa-se que a dissipação turbulenta horizontal é desprezível na escala em estudo. Por outro lado, a exclusão da advecção e a adoção do atrito linear no fundo acarretam perdas na qualidade dos resultados do modelo (Pereira, 1993). Portanto, é necessária uma análise dos erros observados nos resultados e sua relaçāo com os fenômenos físicos acima citados.

No desenvolvimento matemático deste modelo foi considerado o trabalho de Heaps (1972), que utiliza o método espectral de Galerkin para a solução na vertical e considera relaçōes específicas entre o coeficiente de viscosidade turbulenta vertical $\mathrm{N} \mathrm{e} \mathrm{o} \mathrm{coeficiente} \mathrm{de} \mathrm{friç̧ão}$ no fundo do mar $k$, segundo a profundidade $h$, de modo que $\mathrm{kh} / \mathrm{N}=$ cte. Este procedimento resulta nas Equaçōes 4 a 6, que são resolvidas numericamente através de um esquema avançado-retardado no tempo e centrado no espaço, sendo o termo de decaimento tratado no esquema trapezoidal implícito (Haltiner \& Williams, 1980).

Nessas equaçōes, $a_{r}$ é o valor médio de uma função base $\mathrm{f}_{\mathrm{r}}$, na vertical (7); os coeficientes $\mathrm{u}_{\mathrm{r}}$ e $\mathrm{v}_{\mathrm{r}}$ correspondem às transformadas das componentes $u \mathrm{e} v$, sendo expressos em 8 e 9, de modo que u e v são fornecidos pelas expansōes $10 \mathrm{e} 11$, com coeficientes $\phi_{\mathrm{r}}$ expressos em 12 (Harari, 1984, 1985):

$$
\begin{aligned}
& \frac{\partial \eta}{\partial t}+\sum_{r=1}^{\infty}\left\{\frac{\partial}{\partial x}\left(h \phi_{r} u_{r} a_{r}\right)+\frac{\partial}{\partial y}\left(h \phi_{r} v_{r} a_{r}\right)\right\}=0 \\
& \frac{\partial u_{r}}{\partial t}-f v_{r}=-g a_{r} \frac{\partial \eta}{\partial x}-\frac{1}{\rho} a_{r} \frac{\partial P_{a}}{\partial x}+\frac{F_{s}}{\rho h}-\lambda_{r} u_{r} \\
& \frac{\partial v_{r}}{\partial t}+f u_{r}=-\dot{g} a_{r} \frac{\partial \eta}{\partial y}-\frac{1}{\rho} a_{r} \frac{\partial P_{s}}{\partial y}+\frac{G_{s}}{\rho h}-\lambda_{r} v_{r}
\end{aligned}
$$

onde:

$$
\begin{aligned}
& a_{r}=\frac{1}{h} \int_{0}^{h} f_{r} d z \\
& u_{r}=\frac{1}{h} \int_{0}^{h} u f_{r} d z
\end{aligned}
$$

$$
\begin{aligned}
& v_{r}=\frac{1}{h} \int_{0}^{n} v f_{r} d z \\
& u=\sum_{r=1}^{\infty} \phi_{r} u_{r} f_{r} \\
& v=\sum_{r=1}^{\infty} \phi_{r} v_{r} f_{r} \\
& \phi_{r}=\frac{h}{\int_{0}^{n} f_{r}^{2} d z}
\end{aligned}
$$

As equaçōes 5 e 6 possuem coeficientes de decaimento $\lambda_{\mathrm{r}}$, os quais se relacionam com a viscosidade turbulenta vertical através da relação 13 , onde os coeficientes $\alpha_{\mathrm{r}}$ são obtidos pela equação 14.

$$
\begin{gathered}
\lambda_{r}=\frac{\alpha_{r}^{2} N}{h^{2}} \\
\alpha_{r} \operatorname{tg} \alpha_{r}=\frac{k h}{N}=c t \theta .
\end{gathered}
$$

O modelo é processado através da formulação acima, a partir do estado de repouso e com a especificação da tensão de cisalhamento do vento (com as componentes $F_{s}$ e $\mathrm{G}_{\mathrm{s}}$ ) e a pressão atmosférica na superfície $\left(\mathrm{P}_{\mathrm{a}}\right)$; adicionalmente, como condiçōes de contorno, devem ser fornecidos os valores de $\eta$ na borda, sendo os mesmos considerados como a soma de duas parcelas, representando os efeitos astronômicos e meteorológicos, $\eta=\eta_{\mathrm{A}}+\eta_{\mathrm{M}}$. O modelo considera fricção representada pela lei quadrática para a superfície e linear para o fundo.

\section{A grade oceanográfica}

A regiāo modelada compreende uma área de 64.528 $\mathrm{km}^{2}$, onde os elementos de grade foram tomados como quadrados com lados de comprimento $9,28 \mathrm{~km}$. A Figura 2 representa a grade oceanográfica utilizada no modelo e sua batimetria; dos 770 elementos da grade, 446 são oceânicos. Os números de 1 a 8 identificam os pontos onde há dados coletados, os quais foram comparados com resultados do modelo. A estes pontos foram associados os nomes dos acidentes geográficos, conforme a Tabela 1, a fim de facilitar sua localizaçāo no texto subsequente. 


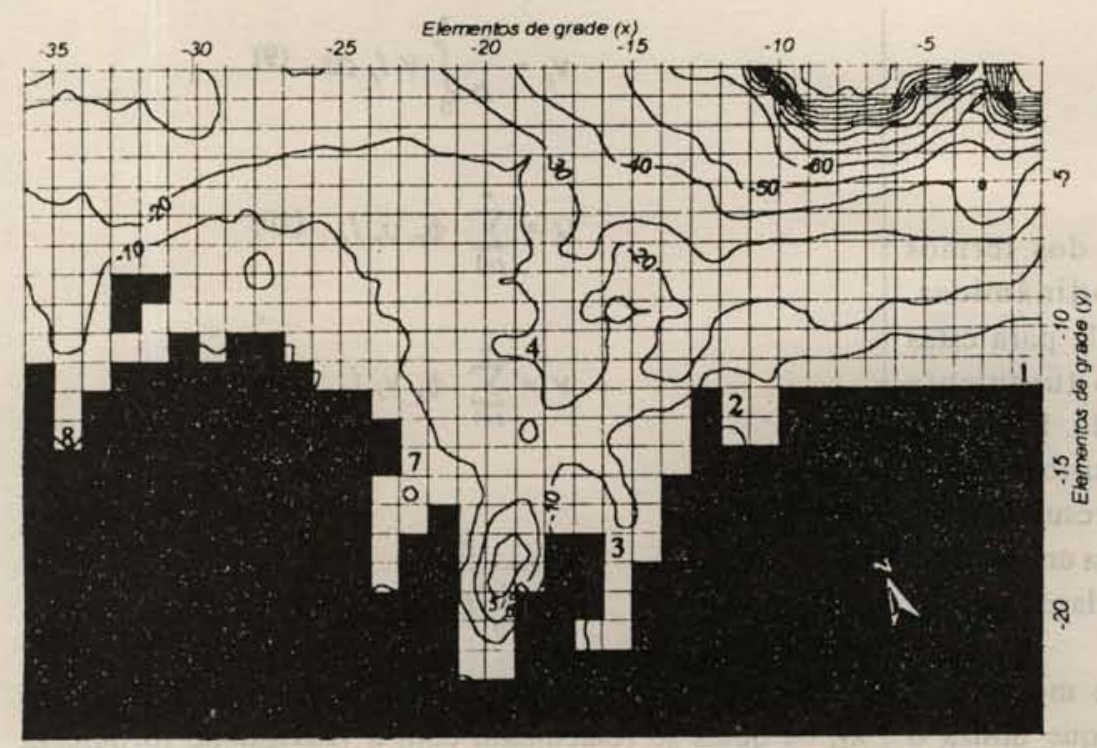

Tabela 1. Pontos na grade

Fig. 2. Grade oceanográfica e sua batimetria, em metros, na área modelada.

A batimetria do fundo foi tomada das cartas náuticas da Diretoria de Hidrografia e Navegaçāo da Marinha do Brasil (DHN), de números 40 e 410 (DHN,1975); para regiōes não hidrografadas, foi utilizado o roteiro de navegaçāo da Marinha do Brasil (DHN,1965). Nestas cartas fica claramente evidenciada a existência de um canal, preservado na batimetria discretizada, utilizado por embarcaçōes como canal de acesso aos Portos existentes na regiāo (Fig. 2).

Através de vários processamentos efetuados com o modelo já calibrado, constatou-se que a sensibilidade do modelo a mudanças na batimetria depende da extensāo da área alterada. Variaçōes envolvendo regiōes relativamente pequenas, mesmo que tenham grande amplitude de oscilação, não afetam significativamente a hidrodinâmica da plataforma como um todo. Desta forma, os pontos da grade coincidentes com o talude continental foram limitados a uma profundidade de $150 \mathrm{~m}$, embora, na realidade, alcancem profundidades da ordem de $1000 \mathrm{~m}$. Esta alteração, em 15 pontos da grade, visou eliminar perturbaçōes irreais geradas localmente pelo modelo. Não foram observadas alteraçōes significativas de amplitude e fase nos pontos do modelo com esta mudança artificial da batimetria, em princípio justificando esta aproximaçāo.

Eventualmente, diminuiçōes no passo de tempo e no espaçamento da grade poderiam eliminar estas instabilidades, porém causando um significativo acréscimo no tempo de computação, sem um correspondente aumento de qualidade nos resultados finais sobre a plataforma.

\section{Processamentos do modelo}

Os processamentos do modelo visaram determinar, basicamente, a circulação na plataforma continental do Maranhāo causada por efeitos astronômicos e meteorológicos. Secundariamente, o modelo foi processado para diversas situaçōes de interesse na área, com o objetivo de estimar a influência de parâmetros dissipativos na circulação. Para estimar a qualidade dos resultados do modelo foi utilizada a relaçāo:

$$
\left(\begin{array}{c}
\text { série temporał } \\
\text { observada }
\end{array}\right)=C_{1} *\left(\begin{array}{c}
\text { série temporal de } \\
\text { resultados do modelo }
\end{array}\right)+C_{0}
$$

Além da regressão linear, foi também calculada a raiz quadrada do erro quadrático médio $(\Delta)$ e o correspondente erro percentual $(\Delta \%)$, entre as séries observadas (ou harmonicamente previstas) e as correspondentes séries temporais calculadas pelo modelo. A calibração do modelo foi feita utilizando-se da relação kh/N constante, igual a 2,00 (Bowden et al., 1959), de modo a ter os coeficientes $k$ e $N / h$ linearmente proporcionais.

Na grade oceanográfica, foram consideradas 17 sub-áreas, identificadas através das características batimétricas locais, cada qual com um valor de N/h constante, obtendo-se a distribuição espacial deste parâmetro como apresentado na Figura 3 (linhas contínuas), onde os valores máximos são atingidos em 
áreas internas, nas Baías; na Figura 3 se encontra, também, a distribuição de $\mathrm{N}$ decorrente da relação de Bowden descrita acima (linhas tracejadas).

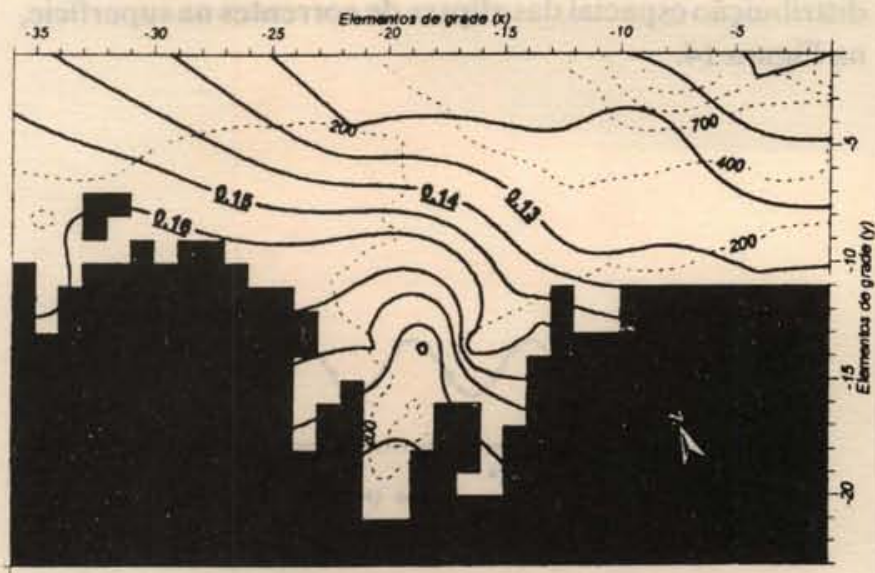

Fig. 3. Valores de $\mathrm{N} / \mathrm{h}$ (em cm/s ) e N $\left(\mathrm{cm}^{2} / \mathrm{s}\right.$ -.--), interpolados para toda a área em estudo.

Os valores dos coeficientes $\mathrm{Ne} k$ encontram-se dentro dos limites estabelecidos na literatura científica para regiōes de plataforma (Davies, 1977;1980), sendo de grande importância na dissipaçāo de energia. Portanto, em princípio, os valores adotados nāo constituem um artifício numérico para favorecer a estabilidade do sistema. De fato, deve ser considerado que o modelo engloba uma área muito rasa, com importantes efeitos dissipativos. Por outro lado, em áreas muito internas, a omissão de efeitos não lineares (tanto advectivos quanto dissipativos) e, principalmente, a baixa resoluçāo de grade adotada, gerando incorreçōes na representação da batimetria e na distribuiçāo espacial dos coeficientes dissipativos, certamente serão responsáveis por erros de fase encontrados nos resultados.

$\mathrm{O}$ modelo foi processado para a componente $\mathrm{M}_{2}$ de maré isoladamente, para a composiçāo das principais componentes astronômicas de maré $\left(\mathrm{M}_{2}, \mathrm{~S}_{2}, \mathrm{~N}_{2}, \mathrm{~K}_{2}, \mathrm{~K}_{1}\right)$, para a circulaçāo média de verāo (Fevereiro), para a circulação média de inverno (Agosto) e para a circulação astronômica em períodos específicos de interesse.

As componentes de maré astronômica foram escolhidas pelo critério de possuírem amplitudes acima de $10 \%$ da componente $\mathrm{M}_{2}$ e por estarem presentes nos espectros de maré em pelo menos dois pontos diferentes da regiâo em estudo. Os valores de amplitude e fase empregados nos contornos oceânicos foram obtidos através de interpolaçāo linear a partir dos resultados do modelo de Schwiderski (1980), considerando-se também dados costeiros disponíveis. Os processamentos para a componente $\mathrm{M}_{2}$ e componentes astronômicas de marć foram iniciados a 00:00 local de 01/06/1980.

A maré meteorológica no contorno aberto foi cstimada com base nos resultados do modelo de circulaçāo geral do Atlântico Sul de Harari (1991), o qual simulou condiçōes típicas de verão e inverno nesta área. Os dados de ventos mensais médios, considerados nos processamentos das correspondentes circulações induzidas por efeitos meteorológicos, foram obtidos de Hellerman (1967), enquanto que os dados de pressão atmosférica sazonal média foram extraídos de van Loon (1984). Os valores meteorológicos considerados nos processamentos do modelo são apresentados nas Figuras 4 e 5.

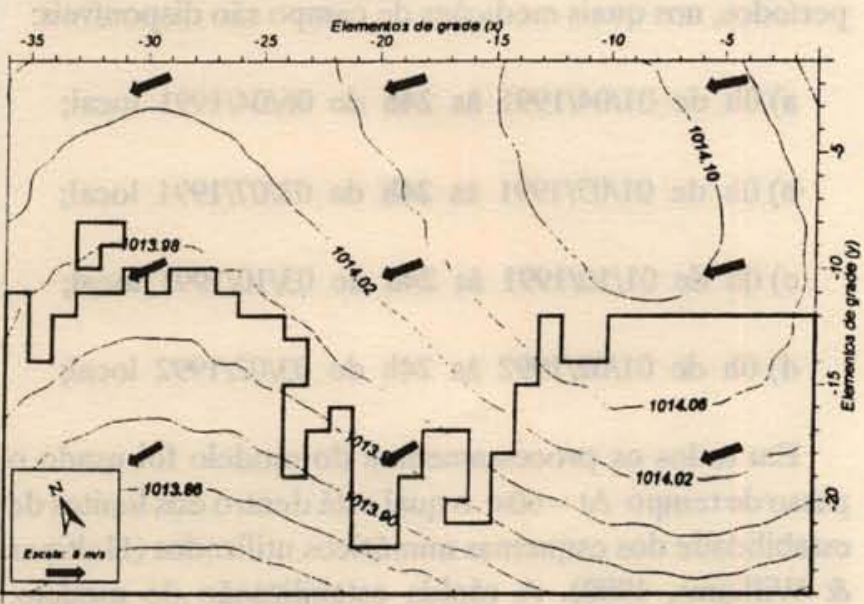

Fig. 4. Dados de vento (ver escala) e pressão atmosférica (em mb) médios no inverno.

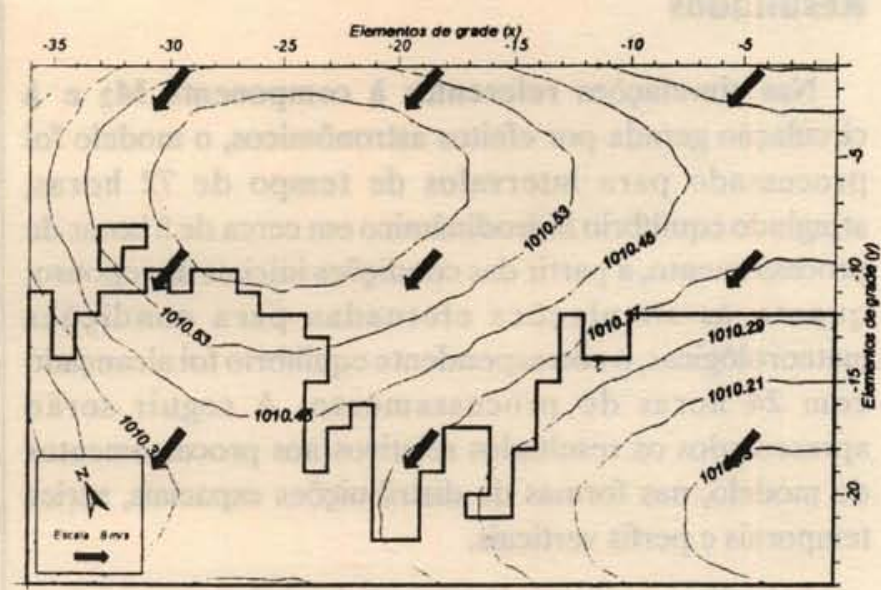

Fig. 5. Dados de vento (ver escala) e pressão atmosférica (em mb) médios no verão. 
Embora existam estimativas mais recentes com certas diferenças em relação aos padrōes de circulação atmosférica adotados, os dados citados foram utilizados em função de sua disponibilidade e de sua razoável representatividade quanto às feiçōes meteorológicas médias locais. Além disso, as correspondentes circulaçōes marítimas induzidas sāo significativamente menores que as de maré, fato que pode ser constatado através da análise de séries temporais obtidas na área.

A última série de processamentos visou reproduzir a circulação total em períodos específicos de interesse, embora tenham sido consideradas somente forçantes de maré na área. Desta forma, a eficácia do modelo é verificada em situaçōes práticas de previsão, comparando-se os resultados com as observaçōes. Os processamentos realizados compreendem os seguintes períodos, nos quais mediçōes de campo sāo disponfveis:

a) $0 \mathrm{~h}$ de $01 / 04 / 1991$ as $24 \mathrm{~h}$ de $06 / 04 / 1991$ local;

b) $0 \mathrm{~h}$ de $01 / 07 / 1991$ às $24 \mathrm{~h}$ de $03 / 07 / 1991$ local;

c) Oh de 01/10/1991 às $24 \mathrm{~h}$ de $03 / 10 / 1991$ local;

d) 0 h de $01 / 02 / 1992$ as 24 h de $03 / 02 / 1992$ local;

Em todos os processamentos do modelo foi usado o passo de tempo $\Delta t=60$ s, o qual está dentro dos limites de estabilidade dos esquemas numéricos utilizados (Haltiner \& Williams, 1980). A rápida estabilização do modelo, principalmente para marés astronômicas, está relacionada à natureza das condiçōes de contorno consideradas, que levam em conta tanto as ondas penetrantes na área como as que se propagam para fora da mesma.

\section{Resultados}

Nas simulaçōes referentes à componente $\mathbf{M}_{2}$ e à circulação gerada por efeitos astronômicos, o modelo foi processado para intervalos de tempo de 72 horas, atingindo equilíbrio hidrodinâmico em cerca de 8 horas de processamento, a partir das condiçōes iniciais de repouso; quanto às simulações efetuadas para condições meteorológicas, o correspondente equilibrio foi alcançado com 24 horas de processamento. A seguir serão apresentados os resultados relativos aos processamentos do modelo, nas formas de distribuiçōes espaciais, séries temporais e perfis verticais.

Componente $\mathbf{M}_{2}$ - Para a componente astronômica de maré $\mathrm{M}_{2}$ sẩo apresentadas: séries temporais de elevaçāo, nas Figuras 6 a 9; as distribuiçōes espaciais das correntes de maré enchente e vazante na superfície, nas Figuras 10 e 11; perfis verticais de máximas correntes horizontais, na Figura 12; isolinhas de elevação e fase, na Figura 13; e a distribuição espacial das elipses de correntes na superfície, na Figura 14.

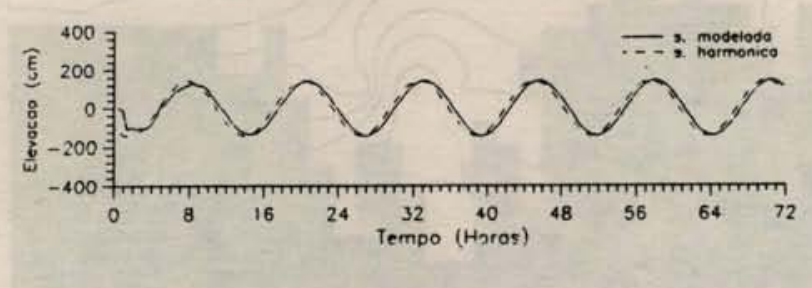

Fig. 6. Elevação da componente $\mathrm{M}_{2}$ no ponto JP15.

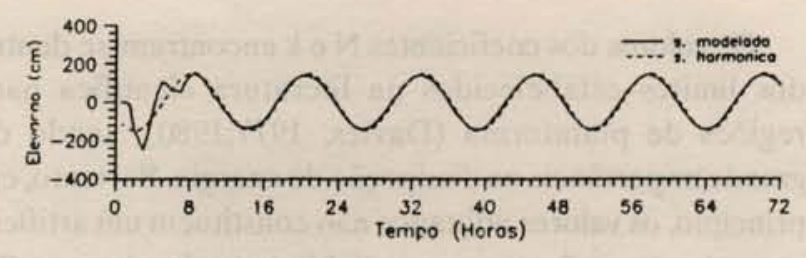

Fig. 7. Elevação da componente $M_{2}$ no ponto Santana.

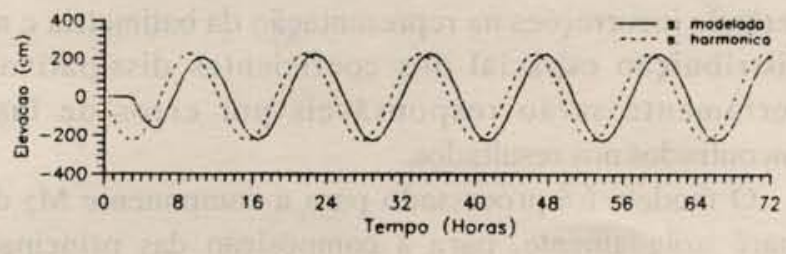

Fig. 8. Elevação da componente $\mathrm{M}_{2}$ no ponto Itaqui.

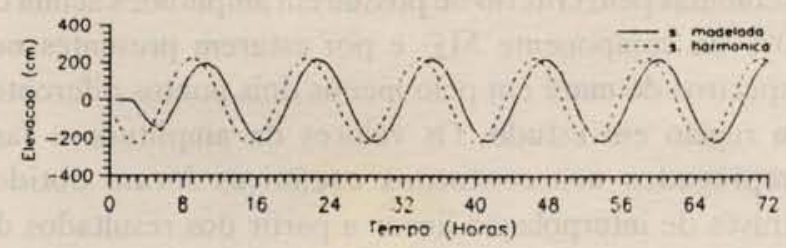

Fig. 9. Elevação da componente $\mathrm{M}_{2}$ no ponto Madeira. 


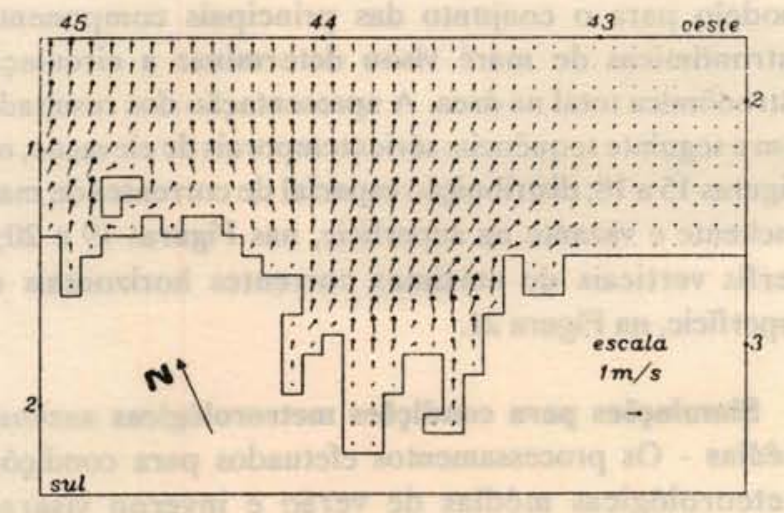

Fig. 10. Correntes vazantes da componente $\mathrm{M}_{2}$, na superfície.

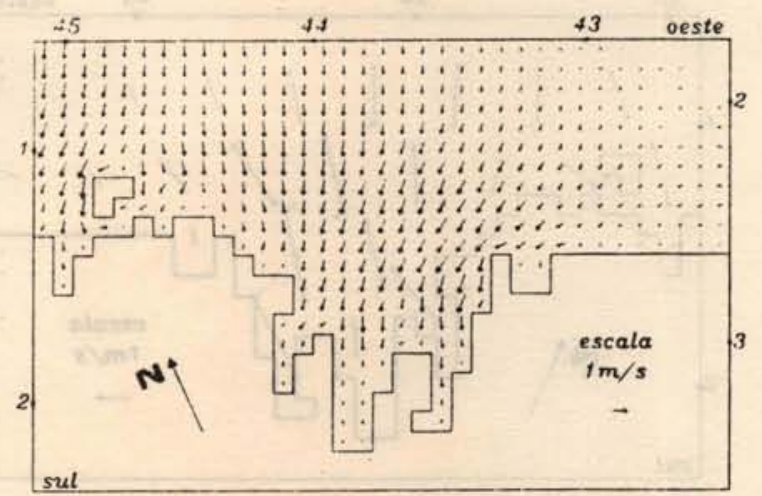

Fig. 11. Correntes enchentes da componente $\mathrm{M}_{2}$, na superfície.

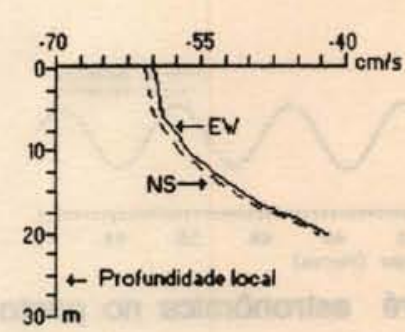

(a)

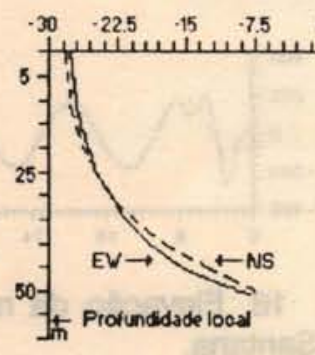

(b)

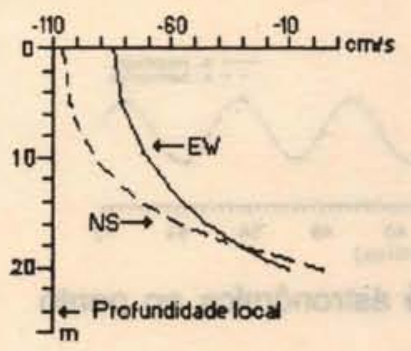

(c)

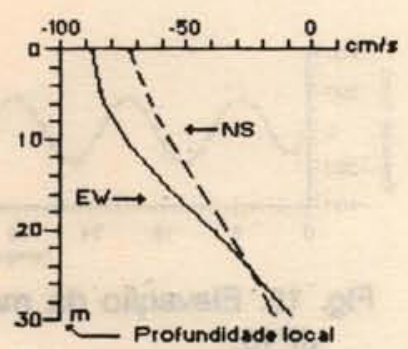

(d)

Fig. 12. Perfis verticais da máxima corrente da $M_{2}$ nos pontos da grade $(x, y)$ :

(a) $-32,05$ (b) $-08,05$ (c) $-18,09$ (d) $-15,07$.

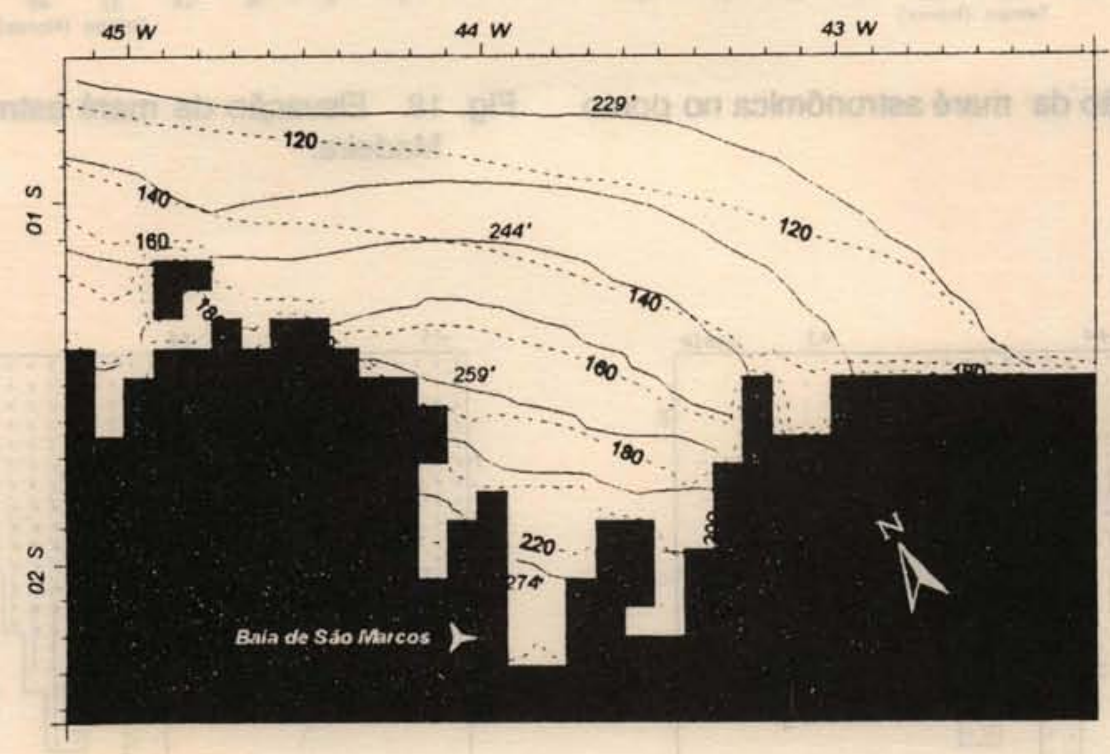

Fig. 13. Isolinhas de amplitude (cm - - -) e de fase (graus _-), relativa a Greenwich, para a componente $\mathrm{M}_{2}$. 


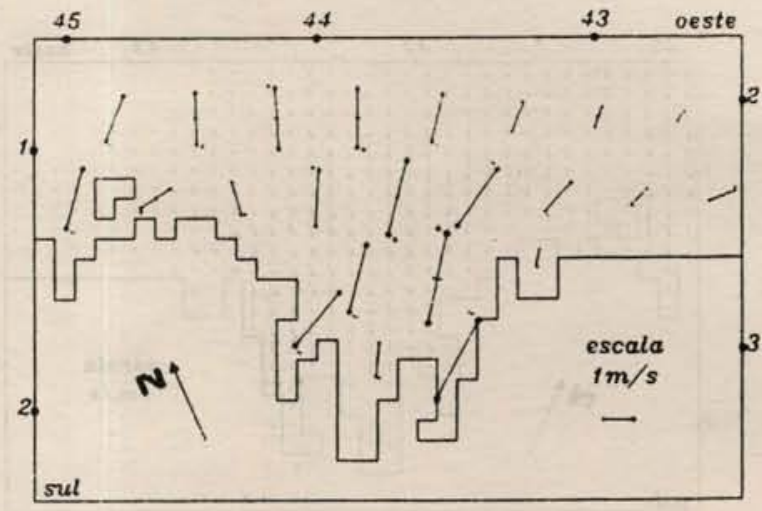

Fig. 14. Elxos das ellipses das correntes de maré da componente $\mathrm{M}_{2}$ na superfície.

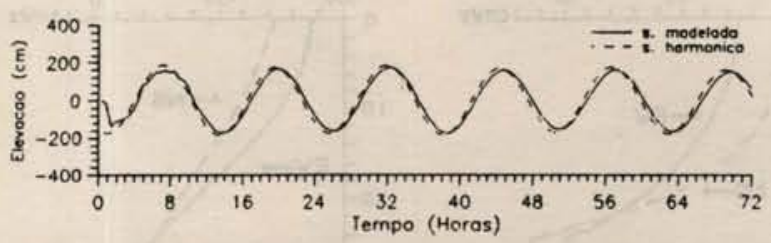

Fig. 15. Elevaçăo da maré astronômica no ponto JP15.

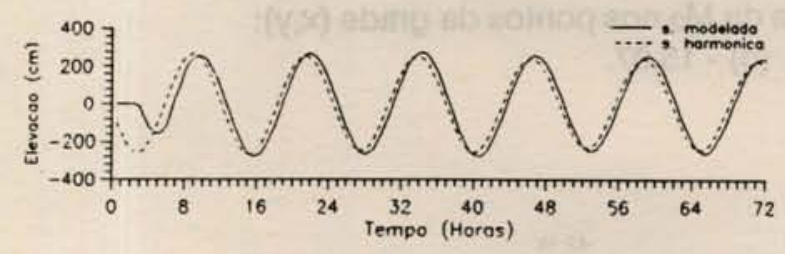

Fig. 17. Elevação da maré astronômica no ponto Itaqui.

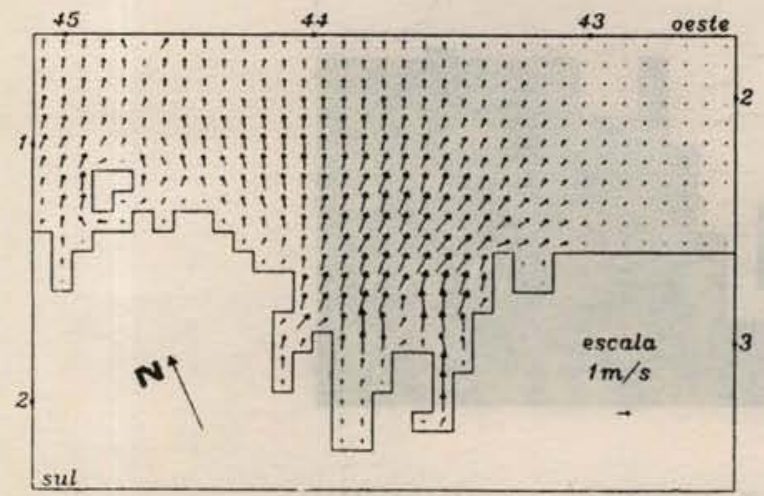

Fig. 19. Correntes de maré astronômica vazante, na superfície.
Componentes astronômicas - O processamento do modelo para o conjunto das principais componentes astronômicas de maré visou determinar a circulação astronômica total na área. A apresentação dos resultados tem a seguinte sequência: séries temporais de elevação, nas Figuras 15 a 18; distribuiçāo espacial de correntes de maré enchente e vazante na superfície, nas Figuras 19 e 20; e perfis verticais de máximas correntes horizontais na superfície, na Figura 21.

Simulaçōes para condiçōes meteorológicas sazonais médias - Os processamentos efetuados para condiçōes meteorológicas médias de verāo e inverno visaram determinar as contribuiçōes dos efeitos do vento, pressão atmosférica e maré meteorológica nos contornos abertos, sobre a circulação total na área. Nas Figuras 22 e 23 estão

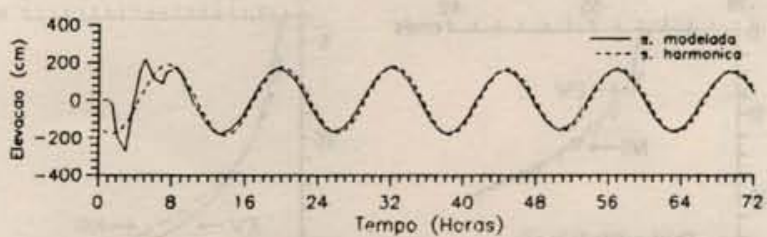

Fig. 16. Elevarăo da maré astronômica no ponto Santana.

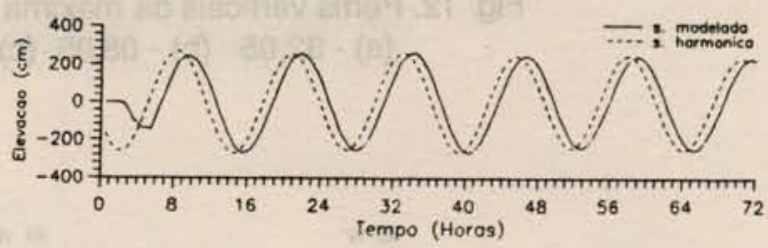

Fig. 18. Elevação da maré astronômica no ponto Madeira.

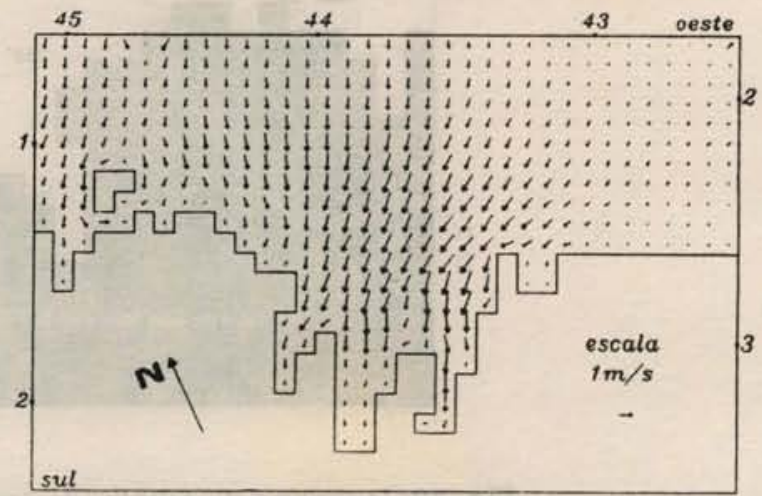

Fig. 20. Correntes de maré astronômica enchente, na superfície. 


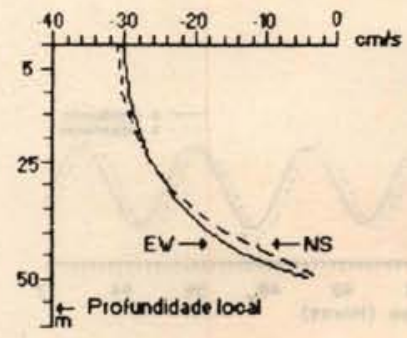

(a)

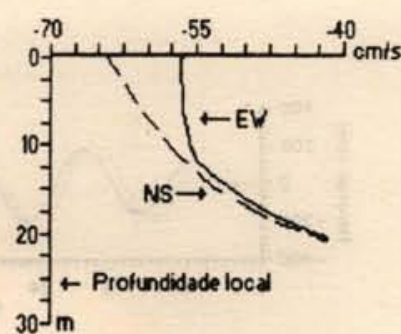

(b)

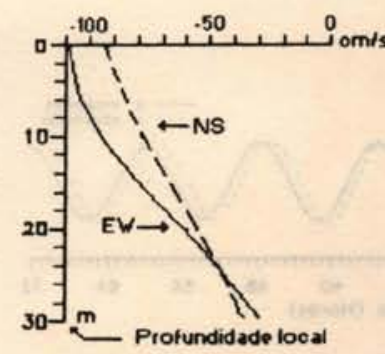

(c)

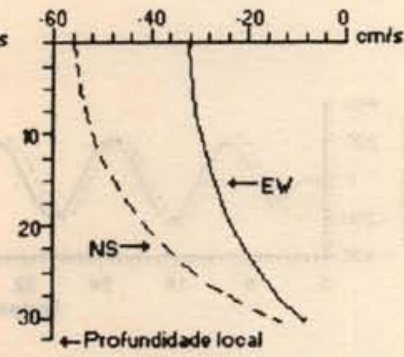

(d)

Fig. 21. Perfis verticais da máxima corrente da maré astronômica nos pontos da grade $(x, y)$ :
(a) $-08,05$
(b) $-32,05$
(c) $-15,07$
(d) $-19,17$.

ilustradas as distribuiçōes espaciais de correntes e elevaçōes devidas aos efeitos meteorológicos sazonais médios na regiẩo. Os perfis verticais de correntes máximas horizontais estão representados na Figura 24, para o verāo, e na Figura 25, para o inverno.

Processamentos em períodos específicos - Outros processamentos foram efetuados, visando comparar seus resultados com dados oceanográficos disponíveis. Desta

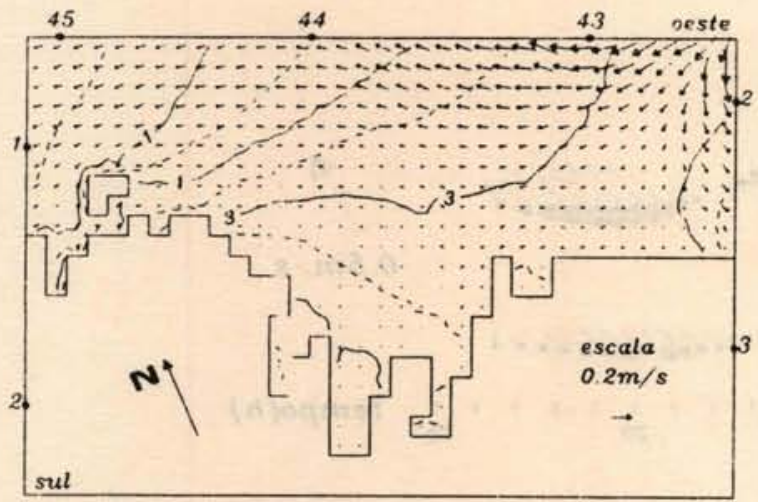

Fig. 22. Correntes e elevações da maré (cm), na superfície, para condições típicas de verão. forma, comparaçōes de resultados de elevação do modelo, no ponto Madeira, com dados de elevação não filtrados, na Ponta da Madeira, estâo ilustrados nas Figuras 26 e 27. Comparaçōes de resultados de correntes do modelo com dados observacionais não filtrados, no nível de $5 \mathrm{~m}$ (fornecidos pelo INPH), são apresentadas nas Figuras 28 e 29.

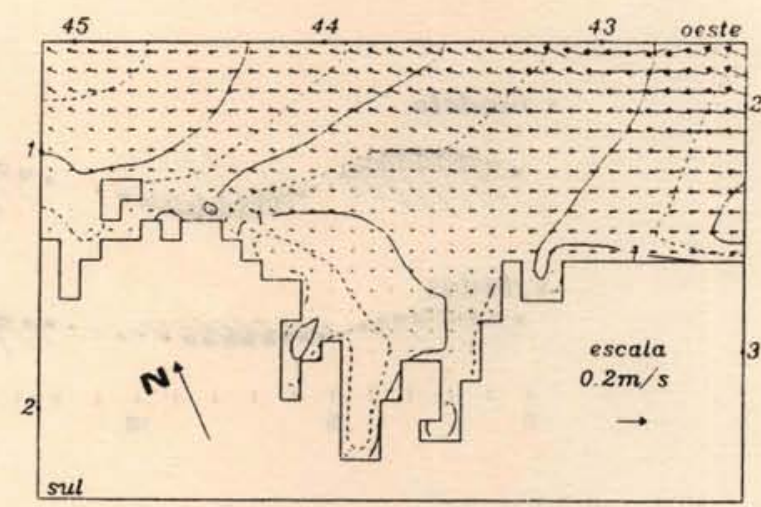

Fig. 23. Correntes e elevações da maré (cm) na superfície, para condiçōes típicas de inverno.

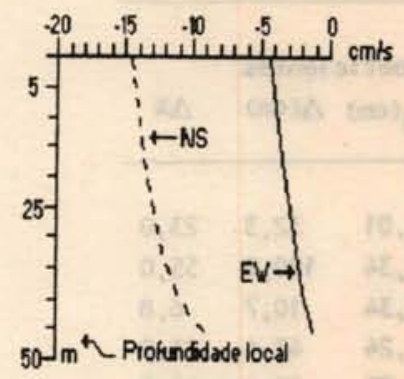

(a)

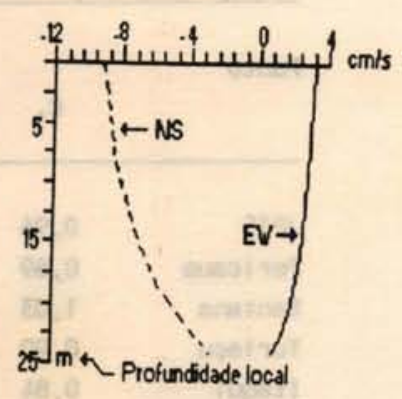

(b)

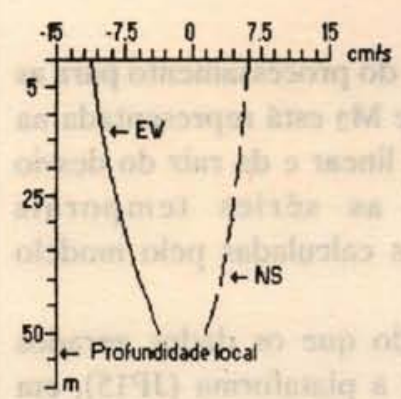

(a)

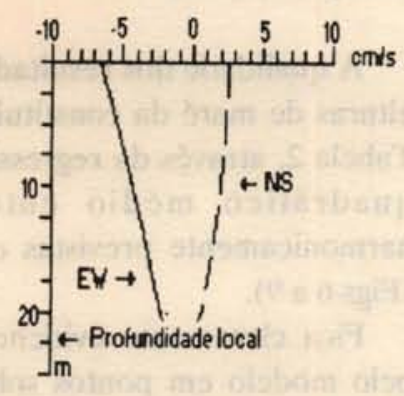

(b)

Fig. 24. Perfis verticais da máxima corrente de verão nos pontos (a) $-05,03$ (b) $-13,07$.

Fig. 25. Perfis verticais da máxima corrente de inverno nos pontos (a) - 05,04 (b) $-13,07$. 


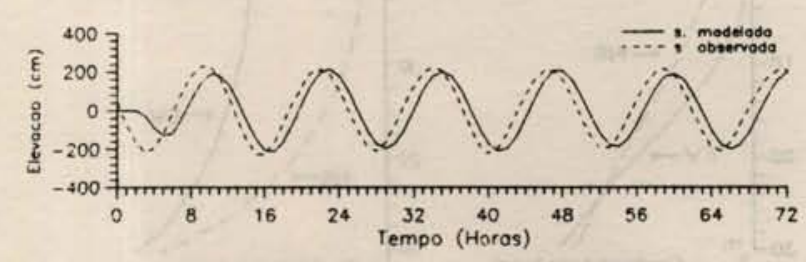

Fig. 26. Elevarăăo de maré no ponto Madeira, de 01/07/91 a 03/07/91.

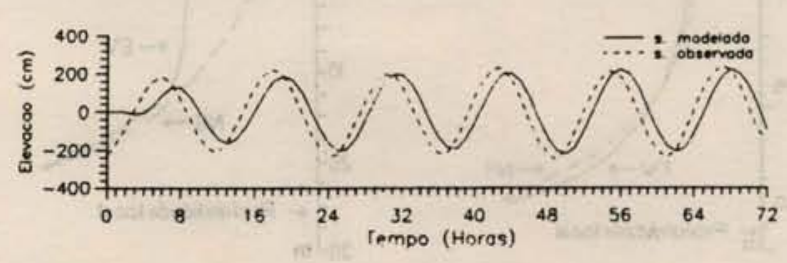

Fig. 27. Elevação de maré no ponto Madeira, de 01/02/92 a 03/02/92.

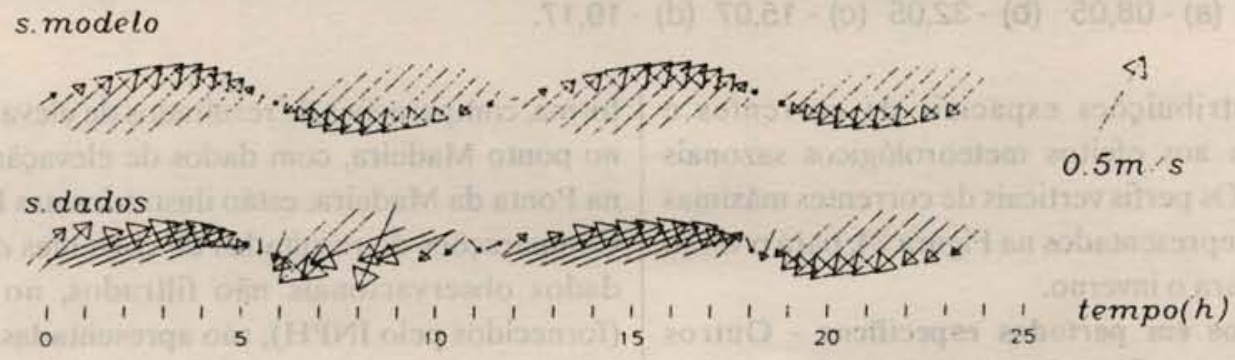

Fig. 28. Séries comparativas de resultados do modelo com dados de corrente no ponto 18,12 da grade, a partir das 00 h00 local do dia 06/04/91.

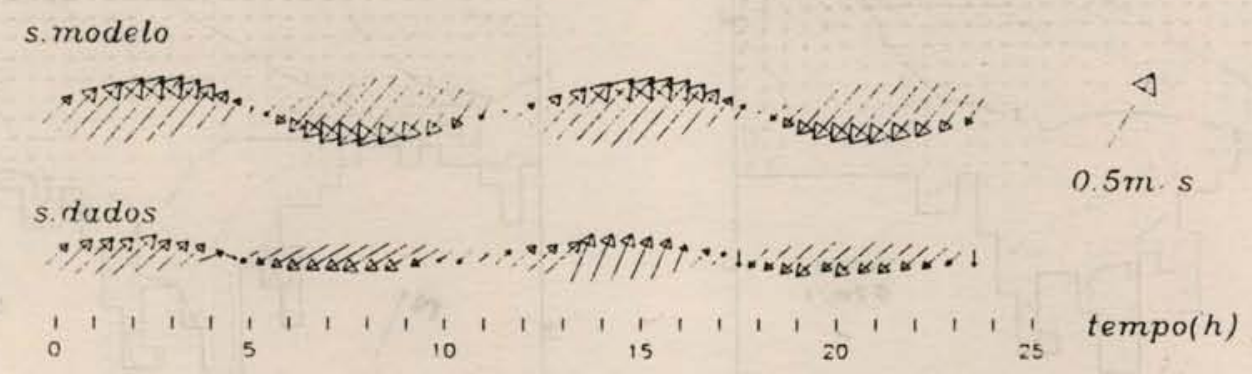

Fig. 29. Séries comparativas de resultados do modelo com dados de corrente no ponto 18,09 da grade, a partir das 00 h00 local do dia 06/04/91 .

\section{Discussão}

\section{Componente $\mathbf{M}_{2}$}

A qualidade dos resultados do processamento para as alturas de maré da constituinte $\mathbf{M}_{2}$ está representada na Tabela 2, através da regressão linear e da raiz do desvio quadrático médio entre as séries temporais harmonicamente previstas e as calculadas pelo modelo (Figs 6 a 9).

Fica claramente evidenciado que os dados gerados pelo modelo em pontos sobre a plataforma (JP15), em áreas expostas da costa (Santana) e no contorno aberto (Preguiças) sâo de melhor qualidade que os dados obtidos para pontos internos às Baías (São José, Madcira e Itaqui).
Tabela 2. Coeficientes de regressão linear e erro padrão no processamento da $\mathrm{M}_{2}$

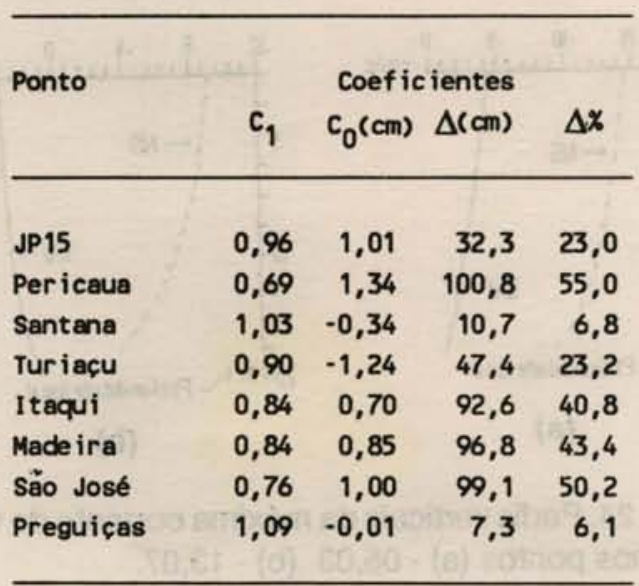


O ponto Pericaua ć um caso particular, por se encontrar numa área de águas rasas onde o fundo oceânico é exposto na baixa-mar. Desta forma, pode-se considerar a área em estudo dividida em duas regiōes com diferentes índices de precisão na simulação, e com os seguintes valores médios dos coeficientes:

a área externa: com $\mathrm{C}_{1}=1,03 \pm 0,06, \mathrm{C}_{0}=0,22 \pm 0,6 \mathrm{~cm}$, $\Delta=17,0 \pm 11,6 \mathrm{~cm}$ e $\Delta \%=12,0 \pm 7,9 \%$.

a área interna: com $\mathrm{C}_{1}=0,81 \pm 0,1, \mathrm{C}_{0}=0,53 \pm 0,9 \mathrm{~cm}$, $\Delta=87,3 \pm 20,2 \mathrm{~cm}$ e $\Delta \%=42,5 \pm 10,9 \%$.

$\mathrm{Na}$ área externa, o modelo reproduz razoavelmente as previsōes harmônicas, apenas subestimando ligeiramente a amplitude de maré local, conforme demonstra o valor obtido para $\mathrm{C}_{1}$ médio. Nas áreas internas, o modelo se encontra ajustado às amplitudes da $\mathbf{M}_{2}$, mas apresenta atrasos de fase bastante significativos, os quais variam de trinta minutos a duas horas, em áreas mais críticas. Dentre os vários fatores que estão associados a estes atrasos, os mais importantes são: a existência de áreas muito rasas próximas à costa, onde o fundo é exposto nas baixamares; a discretização da batimetria e dos contornos terrestres, inserindo erros de representação e nāo permitindo uma distribuição espacial realista para o coeficiente de dissipação em áreas internas; os posicionamentos dos marégrafos, não coincidindo exatamente com os correspondentes pontos da grade; e a eliminação dos termos nâo lineares na formulação do modelo, com atuaçāo localizada em determinadas regiōes, conforme Pereira (1993).

A máxima amplitude atingida pela componente $\mathbf{M}_{2}$ é de $2,30 \mathrm{~m}$, dentro da Baía de Sāo Marcos (Fig. 13). A máxima diferença de fase, entre pontos no contorno aberto e pontos interiores, é de $57,5^{\circ}$, encontrada na Baía de São José; este valor determina o tempo que a onda de maré $\mathrm{M}_{2}$ leva para se propagar do contorno aberto até esta baía, o qual é $1 \mathrm{~h} 59 \mathrm{~min}$.

$O$ intervalo de tempo referido acima pode ser comparado com o tempo estimado para a propagação de uma onda longa, de $2 \mathrm{~h} 04 \mathrm{~min}$, considerando-se a profundidade média igual a 47 metros ao longo de uma radial de $162 \mathrm{~km}$, entre o contorno aberto e a Baía de São José. Embora seja uma comparação qualitativa, pois o desvio padrão na profundidade é grande $( \pm 20 \mathrm{~m}), 0$ resultado obtido é um indicativo que o modelo simula satisfatoriamente a propagação das ondas longas na regiäo.

As correntes da $\mathbf{M}_{2}$ tendem a se manter praticamente normais à costa, nos sentidos para sudoeste e nordeste (enchente e vazante, respectivamente); como exceção, tem-se as proximidades das ilhas representadas por três elementos de grade, onde as correntes sofrem alteraçōes em sua direçāo (Figs 10 e 11). Na parte central da área modelada, as correntes da $\mathbf{M}_{2}$ são nitidamentc alinhadas ao canal existente nesta região, onde as correntes atingem valores máximos e em alguns pontos excedem a $1,5 \mathrm{~m} / \mathrm{s}$. Nas elipses de corrente da $\mathbf{M}_{2}$ é observada a mesma estrutura das correntes descritas acima, devido ao comportamento praticamente unidirecional dessas correntes na regiāo de estudo (Fig. 14).

Os perfis verticais das correntes horizontais da componente de maré $\mathbf{M}_{2}$ sāo determinados pelas hipóteses iniciais e condiçōes de contorno consideradas no modelo. Diante disto, sāo encontradas velocidades horizontais praticamente constantes desde a superfície até a meia água e decaimento dessas velocidades próximo ao fundo (Fig. 12).

\section{Componentes astrômicas da maré}

No segundo processamento do modelo foi obtida a circulação na plataforma devida exclusivamente a efeitos astronômicos, com as componentes $\mathrm{M}_{2}, \mathrm{~S}_{2}, \mathrm{~N}_{2}, \mathrm{~K}_{2}$ e $\mathrm{K}_{1}$. Embora a composiçāo destas ondas não constitua um movimento estritamente periódico, na escala de processamento do modelo de alguns dias, a predominância da componente $\mathbf{M}_{2}$ é notória, praticamente resultando num movimento com seu período.

A circulação gerada pela maré astronômica, representada nas Figuras 15 a 21 , é similar à circulação gerada pela componente $\mathbf{M}_{2}$, fato já esperado, devido à total predominância da componente $\mathrm{M}_{2}$ nos registros de maré em estaçōes costeiras disponíveis na regiāo. A regressão linear e o desvio padrão entre os resultados de altura de maré do modelo e os harmonicamente previstos se encontram na Tabela 3.

Tabela 3. Coeficientes de regressão linear e erro padrão no processamento da maré astronômica

\begin{tabular}{lrrrrr}
\hline & \multicolumn{5}{c}{ Coeficientes } \\
Ponto & $c_{1}$ & $c_{0}(\mathrm{~cm})$ & $\Delta(\mathrm{cm})$ & $\Delta \%$ \\
& & & & & \\
& 1,02 & 1,34 & 34,7 & 18,3 \\
\hline JP15 & 0,70 & 2,10 & 99,6 & 45,9 \\
Pericaua & 1,03 & $-0,67$ & 18,4 & 9,8 \\
Santana & 0,88 & $-1,18$ & 53,7 & 23,2 \\
Turiaçu & 0,81 & 0,63 & 44,8 & 16,7 \\
Itaqui & 0,87 & 1,98 & 95,1 & 35,0 \\
Made íra & 0,82 & 1,96 & 105,1 & 40,9 \\
Säo José & 0,06 & $-0,09$ & 6,3 & 4,1
\end{tabular}


Os valores médios dos cocficientes sāo:

na área externa: $C_{1}=1,04 \pm 0,02, C_{0}=0,2 \pm 0,9 \mathrm{~cm}$, $\Delta=20 \pm 11,9 \mathrm{~cm}$ e $\Delta \%=10,9 \pm 6,1 \%$;

na área interna: $\mathrm{C}_{1}=0,91 \pm 0,1, \mathrm{C}_{0}=0,77 \pm 1,2 \mathrm{~cm}$, $\Delta=79,6 \pm 25,2 \mathrm{~cm}$ e $\Delta \%=32,0 \pm 10,9$.

Tal como na simulação da $\mathrm{M}_{2}$, o modelo é mais preciso na área externa, sobre a plataforma continental, do que nas partes internas, dentro das baías.

A máxima variação do nível do mar ocorre na Baía de São Marcos, no porto de Itaqui, tanto no caso da componente $\mathrm{M}_{2}$ quanto na maré astronômica. Embora a circulação gerada pelas cinco componentes astronômicas tenha as mesmas feiçōes gerais da circulação gerada pela componente $\mathrm{M}_{2}$ isoladamente, na verdade estas circulaçōes diferem quantitativamente, conforme evidenciam as Tabelas 2 e 3 . De fato, uma amplificação entre 20 e $25 \%$ é observada na altura de maré, quando inseridas as componentes harmônicas $\mathrm{S}_{2}, \mathrm{~N}_{2}, \mathrm{~K}_{2}$ e $\mathrm{K}_{1} \mathrm{em}$ adição à $\mathbf{M}_{2}$. Valores máximos de corrente de superfície ao longo de uma radial, desde áreas internas na Baía de Sāo Marcos até pontos externos sobre a plataforma, se encontram na Tabela 4. As coordenadas de localização destes pontos são referentes à grade apresentada na Figura 2.

O comportamento da direçāo preferencial da corrente, observado na Tabela 4 , novamente demonstra a similaridade entre a circulação devida à componente $\mathrm{M}_{2} \mathrm{e}$ a devida às cinco componentes astronômicas principais. Também nas correntes nota-se uma intensificação das correntes de maré em aproximadamente $25 \%$ em relaçāo às correntes da $\mathrm{M}_{2}$.

Tabela 4. Intensidade e direção das correntes máximas, com coordenadas de localização referidas à grade

\begin{tabular}{|c|c|c|c|c|c|}
\hline \multicolumn{2}{|c|}{$\begin{array}{c}\text { Ponto } \\
x, y \\
\text { da grade }\end{array}$} & \multicolumn{2}{|c|}{ Componente $\mathrm{M}_{2}$} & \multicolumn{2}{|c|}{$\begin{array}{l}\text { Componentes } \\
\text { Astronômicos }\end{array}$} \\
\hline & & $\mathrm{cm} / \mathrm{s}$ & $\left({ }^{\circ}\right)$ & $\mathrm{cm} / \mathrm{s}$ & $\left({ }^{\circ}\right)$ \\
\hline 19 & 20 & 41,9 & 269,3 & 51,6 & 269,3 \\
\hline 19 & 18 & 41,7 & 250,2 & 50,8 & 250,1 \\
\hline 19 & 16 & 134,0 & 269,7 & 162,9 & 269,7 \\
\hline 18 & 14 & 134,71 & 247,9 & 63,6 & 248,1 \\
\hline 18 & 12 & 148,21 & 248,7 & 79,6 & 248,7 \\
\hline 18 & 09 & 136,71 & 255,7 & 65,9 & 255,7 \\
\hline 17 & 09 & 142,11 & 248,8 & 72,8 & 248,8 \\
\hline 17 & 10 & 127,22 & 249,9 & 154,6 & 249,9 \\
\hline
\end{tabular}

Circulaçōes devidas a efeitos meteorológicos sazonais médios

No verão (Fig. 22), as maiores elevaçōes devidas a efeitos meteorológicos ocorrem dentro do Golfo do Maranhāo, com valores máximos de $5 \mathrm{~cm}$ e gradiente de elevaçāo aproximadamente paralelo à costa, de noroeste para sudeste. A circulação gerada é predominantemente para noroeste, sendo parte do Ramo Norte da Corrente do Brasil, atingindo maiores valores em intensidade de corrente, da ordem de $28 \mathrm{~cm} / \mathrm{s}$, próximo à quebra da plataforma, na regiāo mais profunda da área, resultando então em expressivos transportes locais.

No inverno (Fig. 23), as maiores elevaçōes ocorrem dentro do Golfo do Maranhāo e nos contornos abertos a leste, atingindo máximos de $3 \mathrm{~cm}$, com gradientes nos sentidos noroeste-sudeste (paralelo à costa) e nordeste-sudoeste (entrando no Golfo do Maranhāo). A circulaçāo gerada é aproximadamente paralela à costa, para noroeste, com valores máximos da ordem de $15 \mathrm{~cm} / \mathrm{s}$; as intensidades de corrente mais significativas novamente se encontram ao longo do contorno oceânico aberto, sobre a regiāo mais profunda, sendo parte do Ramo Norte da Corrente do Brasil. Também nesta simulaçāo há um maior transporte de volume nas regiōes mais profundas.

A importância da maré meteorológica nos contornos abertos é significativa, com as correntes na área sendo praticamente determinadas por estas condiçōes de contorno, além do efeito direto do vento local. Observa-se que os efeitos da pressāo nāo sāo importantes localmente na circulaçāo; por outro lado, o efeito do vento é sensível nos perfis verticais de correntes. Nestes perfis, tanto no verão (Fig. 24) como no inverno (Fig. 25), observa-se na direçāo uma pequena rotação com o aumento da profundidade, nas duas simulaçōes de correntes sazonais médias.

Considerando os resultados obtidos, observa-se que, em condiçōes meteorológicas típicas, a circulação na área em estudo é basicamente devida a efeitos da maré astronômica, com a contribuiçāo meteorológica nāo chegando a atingir $0,2 \%$ da circulação total; nesta estimativa, obviamente são excluídas condiçōes atípicas de vento e pressão na área, não discutidas neste trabalho.

\section{Processamentos em períodos específicos}

Os resultados apresentados neste item tiveram por objetivo analisar o comportamento do modelo em situaçōes práticas de previsāo da circulação oceânica. Nas Figuras 26 e 27 são comparados dados de maré observados na Ponta da Madeira com os correspondentes resultados do modelo. Constata-se, neste caso, que o comportamento do modelo é satisfatório na simulação da elevação da maré local, embora o erro na fase seja de aproximadamente 60 
min. Os cocficientes de regressão linear c do erro padrão entre os dados e resultados do modelo estâo identificados abaixo (considerando resultados de 24 a 72 horas de processamento):

Processamento a partir de 01/07/91

$\mathrm{C}_{1}=0,9227 \mathrm{C}_{0}=6,6464 \mathrm{~cm} \quad \Delta=88,5 \mathrm{~cm} \Delta \%=36,4 \%$ Processamento a partir de 01/02/92

$C_{1}=0,9193 C_{0}=-10,2633 \mathrm{~cm} \Delta=90,3 \mathrm{~cm} \Delta \%=37,7 \%$

Os valores de $\mathrm{C}_{0}, \mathrm{C}_{1}$ e $\Delta$ acima apresentados demonstram que o nível de correlação, entre os resultados do modelo e a série de elevação observada, é similar ao das correspondentes comparaçōes para a $\mathrm{M}_{2}$ e a maré astronômica no ponto Madeira. É importante ressaltar que os resultados dos processamentos em períodos específicos foram comparados a observaçōes diretas, sem nenhuma filtragem; e os valores relativamente altos do erro padrão obtidos para o ponto Madeira derivam do fato deste ser um dos pontos internos, os quais sempre apresentaram maiores desvios, como nos processamentos da $\mathbf{M}_{2}$ e da maré astronômica.

Os resultados de correntes do modelo, relativos ao processamento a partir de 06/04/91, são ilustrados nas Figuras 28 e 29 , com comparaçōes vetoriais dos mesmos com dados de campo (não filtrados). Observa-se nessas figuras uma razoável concordância em intensidade, dircção e fase dos resultados do modelo com observaçōes na área, a qual pode também ser verificada na Tabela 5, onde são apresentados os resultados da análise estatística das componentes EW e NS, através de regressão linear e do erro médio entre as correspondentes séries temporais. No entanto, é preciso salientar que os dados utilizados também possuem uma incerteza de medição do aparelho, de $\pm 11,25^{\circ}$, relacionada ao intervalo de integração da medida, de $22,5^{\circ}$.

Tabela 5. Coeficientes, de regressão linear e erro padrão para correntes (processamentos em períodos especfficos com dados)

\begin{tabular}{|c|c|c|c|c|c|}
\hline \multirow{2}{*}{$\begin{array}{c}\text { Ponto } \\
x y\end{array}$} & \multirow[t]{2}{*}{ Dir. } & \multicolumn{3}{|c|}{ Coeficientes } & \multirow[b]{2}{*}{$\Delta \%$} \\
\hline & & $c_{1}$ & $\mathrm{c}_{0} \mathrm{~cm} / \mathrm{s}$ & $\Delta \mathrm{cm} / \mathrm{s}$ & \\
\hline \multirow[t]{2}{*}{$18 \quad 12$} & EW & 1,17 & 4,97 & 10,4 & 24,0 \\
\hline & NS & 0,72 & $-4,33$ & 12,7 & 30,0 \\
\hline \multirow[t]{2}{*}{17} & EW & 0,68 & 3,44 & 13,3 & 28,0 \\
\hline & NS & 0,95 & $-1,61$ & 9,9 & 28,0 \\
\hline \multirow[t]{2}{*}{$17 \quad 09$} & EW & 0,89 & $-0,64$ & 10,6 & 25,6 \\
\hline & NS & 0,36 & $-2,04$ & 18,4 & 47,1 \\
\hline \multirow[t]{2}{*}{1809} & EW & 0,65 & $-2,02$ & 9,8 & 29,6 \\
\hline & NS & 0,53 & 1,10 & 14,6 & 30,7 \\
\hline
\end{tabular}

O nívcl médio diário do mar no ponto Madeira, para o ano de 1991, possui máximos de elevação da ordem de 5 cm (Pereira, 1993). Esta é uma informação de grande interesse, já que estes valores foram também previstos pelo modelo nas simulaçōes de invernoe verão. A concordância da ordem de grandeza destas amplitudes está provavelmente relacionada à relativamente pequena variabilidade sazonal das condições climáticas na regiāo.

Portanto, em princípio, o modelo pode ser usado em previsōes da circulação, sobretudo nas áreas externas da plataforma do Estado do Maranhāo, mesmo que sejam consideradas apenas forçantes de natureza astronômica. Isto porque as elevaçōes e correntes geradas por efeitos meteorológicos são bem mais fracas que as correspondentes elevaçōes e correntes de maré, como também demonstrado nas simulaçōes de circulaçāo de maré e de condiçōes meteorológicas sazonais médias (verāo e inverno).

Havendo previsões meteorológicas na escala do modelo, é óbvio que sua implementação deve aprimorar os resultados de previsão da circulação oceânica. Porém, na ausência de previsōes meteorológicas, considerando as características hidrodinâmicas da área modelada, o uso do modelo para previsâo da circulação, impondo apenas forçantes de natureza astronômica, conduz a resultados razoavelmente satisfatórios. Quanto a previsōes nas baías, onde os atuais resultados nāo são satisfatórios, este modelo ainda é bastante útil, pois seus resultados em áreas externas podem ser usados como condiçōes de contorno para modelos de pequena escala aninhados, para as áreas internas rasas.

\section{Consideraçōes adicionais}

Algumas consideraçōes adicionais sobre a simulaçāo da propagação da $\mathrm{M}_{2}$, relacionadas a fenômenos físicos que ocorrem na área, podem ser feitas:

a - Defant (1961) demonstra que, em condiçỏes ideais, sem atrito, se tem a ortogonalidade das isolinhas de fase em relaçāo às de amplitude, tanto para ondas progressivas como estacionárias; entretanto, quando é inserido e aumentado o atrito no sistema de equaçōes, observa-se uma tendência de alinhamento das isolinhas de amplitude e fase.

Confrontando a distribuição espacial das isolinhas de amplitude e de fase (Fig. 13), observa-se que estas se mantêm aproximadamente paralelas, demonstrando que efeitos de atrito são determinantes na circulação de toda a área considerada no modelo.

b - Comparando as séries de amplitude da maré $\mathbf{M}_{\mathbf{2}}$ com as correspondentes séries de intensidade das correntes de maré, sendo ambas resultantes da modelagem, nota-se que, nas áreas mais afastadas da costa, 
as ondas de maré sāo predominantemente progressivas; já em áreas internas essas ondas apresentam características de ondas estacionárias. Este mesmo comportamento é observado se considerados dados de elevaçāo e correntes de maré nos pontos JP1'5 e Madeira. Neste caso, a diferença de fase entre a máxima elevação e máxima corrente é da ordem de $30^{\circ}$ para o ponto JP15 e $70^{\circ}$ para o ponto Madeira. Tal constataçāo permite inferir que, embora o erro de fase dentro da Baía de São Marcos seja grande, o modelo consegue simular adequadamente a hidrodinâmica local.

Quanto à ocorrência de ressonância, o período de oscilaçāo de uma onda estacionária, calculado através da fórmula de Merian (Pugh, 1987) para toda a extensão da plataforma (Pereira, 1993), de $12 \mathrm{~h} 50 \mathrm{~min}$, é um valor bastante próximo do período da maré semi-diurna. Este fato, associado à Figura 30 , permite inferir, embora não de forma conclusiva, que efeitos de ressonância podem estar presentes na área.

c- Como um fenômeno tipicamente costeiro, a refração pode ser observada, em diferentes escalas, nas isolinhas de fase da Figura 13.

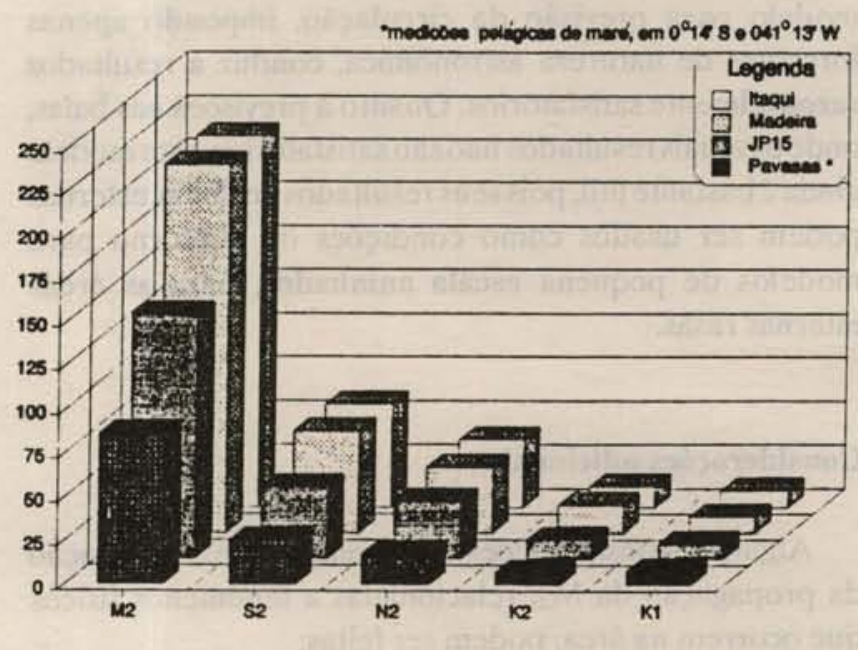

Fig. 30. Amplitudes das principais componentes astronômicas de maré (em cm).

Em pequena escala, de um a dois elementos de grade, sảo observadas sucessivas convergências e divergências nas isolinhas de fase ao longo da linha da costa, provocando concentraçōes e compensatoriamente dispersōes da energia da onda de maré $\mathbf{M}_{2}$ na costa, com efeitos sensíveis na amplitude da maré local. Relacionadas a irregularidades no contorno terrestre, estas variaçōes são fortes indicadoras de refraçāo ocorrendo nesta escala. Em meso-escala, cobrindo toda a regiāo modelada, a refração é responsável pela curvatura nas isolinhas de fase, quando estas atingem a área limite do canal na plataforma (Fig. 13).
No canal, onde as profundidades sāo maiores, a velocidade de fase da onda incidente é aumentada, gerando a curvatura das linhas cotidais acima descrita.

Desta forma, tem-se uma indicação clara da influência da batimetria, geometria do contorno terrestre e atrito, na circulaçāo da maré na Plataforma Continental do Estado do Maranhão.

\section{Conclusões}

Este trabalho foi subdividido em cinco etapas, com as seguintes simulaçōes: componente $\mathbf{M}_{2}$ isoladamente, componentes astronômicas de maré conjuntamente, circulação devida a efeitos meteorológicos médios de inverno, circulação devida a efeitos típicos de verāo e processamentos em períodos específicos de interesse. As conclusōes sobre estes processamentos serāo a seguir descritas (Pereira,1993).

Testes de calibração do modelo definiram a grade e sua batimetria de fundo (Fig. 2), a partir de um espaçamento horizontal de $9,28 \mathrm{Km}$. O aspecto mais importante na calibração do modelo encontra-se na determinação dos coeficientes dissipativos na área modelada, especialmente o coeficiente de viscosidade turbulenta vertical $\mathrm{N}$, cuja distribuição se encontra na Figura 3; quanto ao coeficiente de friç̧āo linear no fundo $k$, este foi definido a partir da relação de Bowden, em função dos valores determinados para $\mathrm{N}$.

Os mapas cotidais (Fig. 13) indicam um aumento da amplitude da $\mathrm{M}_{2}$, desde valores abaixo de $1,0 \mathrm{~m}$ (no contorno aberto) até valores acima de $2,0 \mathrm{~m}$ (no interior das baías de São José e São Marcos). A propagação da $\mathbf{M}_{2}$, do limite aberto à Baía de Sāo José, requer $1 \mathrm{~h} 59 \mathrm{~min}$, valor muito próximo à velocidade de fase de uma onda longa numa região de profundidade média igual a $47 \mathrm{~m}$, a qual corresponde a $2 \mathrm{~h} 04 \mathrm{~min}$. As correntes e os transportes da $\mathbf{M}_{2}$ sāo muito influenciados pelo "canal" que liga as Baías acima citadas e a borda aberta oposta, havendo predominância do sentido sudoeste-nordeste na circulaçāo. Na regiāo do canal as correntes atingem valores máximos, chegando a exceder $1,5 \mathrm{~m} / \mathrm{s}$. As elipses de corrente da $\mathrm{M}_{2}$ (Fig. 14) também refletem esse caráter intenso e praticamente unidirecional das correntes. Os perfis verticais das correntes horizontais da $\mathbf{M}_{2}$ indicam a grande influência do atrito no fundo e da viscosidade turbulenta vertical, havendo acentuado decaimento da velocidade com a profundidade a partir da meia água (Fig. 12).

Os efeitos de atrito e viscosidade sāo também notórios na distribuiçāo relativa das isolinhas de amplitude e de fase da $\mathrm{M}_{2}$, que se mantêm paralelas praticamente em toda a área modelada, efeito descrito em Defant (1961). A onda de maré é predominantemente progressiva nas áreas 
externas; já em algumas áreas internas, como na Baía de São Marcos, há tendência a um comportamento estacionário, fato este comprovado por mediçōes na área (Fig. 30). Outro fator a ser considerado é a coincidência do período de oscilaçāo das componentes semi-diurnas com o período de oscilação estimado para a plataforma continental, segundo a fórmula de Merian (Pugh,1987). No canal existente na plataforma e em pequena escala, bem como nas linhas de contorno da costa, são observados efeitos de refraçāo da onda de maré nas linhas cotidais da componente $\mathrm{M}_{2}$; estes efeitos atuam na concentração e dispersão de energia local (Defant, 1961).

Os resultados para as componentes astronômicas principais ( $\mathrm{M}_{2}, \mathrm{~S}_{2}, \mathrm{~N}_{2}, \mathrm{~K}_{2}$ e $\left.\mathrm{K}_{1}\right)$ são bastante similares aos encontrados para a componente $\mathbf{M}_{2}$, demonstrando a importância desta na circulaçāo gerada por efeitos astronômicos. Entretanto, embora mantendo as características gerais da $\mathbf{M}_{2}$, a composiçāo das principais componentes astronômicas provoca nas alturas e nas intensidades das correntes uma amplificação de aproximadamente $25 \%$ em relação aos correspondentes valores da $\mathrm{M}_{2}$ (Figs 19 e 20 e Tab. 4).

As simulaçōes da $\mathrm{M}_{2}$ e da maré astronômica indicam que as condiçōes de borda, a batimetria, a geometria do contorno terrestre e o atrito são os fatores determinantes na circulação gerada por efeitos astronômicos na plataforma do Estado do Maranhảo.

Nas simulaçōes para condiçōes meteorológicas médias, foram consideradas duas estaçōes do ano, inverno e verāo. Foram introduzidos no modelo dados típicos de vento e pressāo na superfície e de elevação de maré meteorológica nos contornos abertos, nestas estaçōes. Os resultados obtidos em ambos os casos demonstram que os efeitos meteorológicos na circulação geral são pequenos, com elevaçōes máximas de $5 \mathrm{~cm}$ e correntes máximas de $28 \mathrm{~cm} / \mathrm{s}$ no verão, enquanto que no inverno os correspondentes valores máximos sāo de $3 \mathrm{~cm}$ e $15 \mathrm{~cm} / \mathrm{s}$ (Figs 22 e 23). Esses valores máximos de correntes são paralelos à costa, sendo parte do Ramo Norte da Corrente do Brasil. Nestes processamentos, a distribuição espacial das correntes é sensivelmente influenciada pelas condiçōes impostas pela elevação da maré meteorológica nos contornos abertos, além do efeito direto do vento local.

As simulaçōes para períodos específicos de interesse visaram determinar o comportamento do modelo em situaçōes reais de previsāo, tendo sido escolhidos períodos de processamento em que havia dados disponíveis na regiāo (Figs 26 a 29). Em princípio, o modelo pode ser usado em previsōes da circulação nas áreas externas da plataforma do Estado do Maranhāo, mesmo que sejam consideradas apenas as forçantes de natureza astronômica, tendo em vista as características hidrodinâmicas da área, com elevaçōes e correntes de maré muito mais intensas que as induzidas por efeitos meteorológicos.

Como conclusão final, as simulaçōes do modclo foram de boa qualidade na plataforma e de menor precisão nas baías e áreas internas rasas, imprecisāo esta principalmente relacionada a uma representaçāo insuficiente da batimetria nestas áreas, nāo permitindo uma distribuiçåo espacial realista para os coeficientes dissipativos. Uma melhor representação da hidrodinâmica nessas regiōes costeiras poderá ser obtida através de um modelo aninhado, em pequena escala, com espaçamento de grade entre 500 e $1000 \mathrm{~m}$, o qual deverá incluir termos advectivos nāo lineares e lei de fricção quadrática, e que poderá utilizar resultados do presente modelo como condiçōes de contorno nos limites abertos.

\section{Referências bibliográficas}

BOWDEN, K. F., FAIRBAIRN, L. A. \& HUGHES, P. 1959. The distribution of shearing stresses in tidal currents, Geophys. J. R. astron. Soc., 2:288-305.

DAVIES, A. M. 1977. Three-dimensional model with depth varying eddy viscosity. In: Nihould, J. C. J. ed. Bottom Turbulence: proc. of the $8^{\text {th }}$ Intern. Liège Colloq. on Ocean Hydrodynamics. Amsterdam, Elsevier, p. 27-48.

1980. On formulating a three-dimensional hydrodynamic sea model with an arbitrary variation of vertical eddy viscosity. Comp. Meth. Appl. Mech. Eng., (22):187-211.

\& STEPHENS, C. V. 1983. Comparison of the finite difference and Galerkin methods as applied to the solution of the hydrodynamical equations. Appl. Math. Modelling, (7):226-240.

DEFANT, A. 1961. Physical oceanography. Pergamon Press, vol. 1, 729p. vol. 2, 598p.

DIRETORIA DE HIDROGRAFIA E NAVEGAÇÃO (DHN). 1975. Cartas náuticas, n² 40 e 410.

1965. Roteiro Brasil. Parte I, 403p.

FERRAZ, L. A. C. 1975. Tidal and current prediction for the Amazon's north channel using a hydrodynamical-numerical model. M.Sc. Dissertation. California, Naval Postgraduate School. 85p. 
HALTINER, G. J. \& WILLIAMS R. T. 1980. Numerical prediction and dynamic meteorology. New York, John Wilcy, 477p.

HARARI, J. 1984. Modelo numérico hidrodinâmico tri-dimensional linear da plataforma continental sudeste do Brasil. Tese de doutorado. Universidade de São Paulo, Instituto Astronômico e Geofísico, 203p.

1985. Desenvolvimento de um modelo numérico hidrodinâmico tri-dimensional linear, para a simulação e a previsão da circulação na plataforma brasileira, entre $23^{\circ}$ e $26^{\circ} \mathrm{S}$. Bolm. Inst. oceanogr., S Paulo, 33:159-191.

1991. Modelo numérico hidrodinâmico tri-dimensional linear do Oceano Atlântico Sul. Tese de livre-docência. Universidade de São Paulo, Instituto Oceanográfico. 403 p.

HEAPS, N. S. 1972. On the numerical solution of the three-dimensional hydrodynamical equations for tides and storm surges. Mém. Soc. r. Sci. Liège, 6(2):143-180.

HELLERMAM, S. 1967. An updated estimate of the wind stress on the world ocean. Mon. Weath. Rev., 95(9):607-626.
LOON, H. van 1984. Climates of the oceans. In: World Survey of Climatology, v. 15. Amsterdam, Elsevier, 716p.

PEREIRA, J. E. R. 1993. Modelagem numérica tri-dimensional da circulaçāo na plataforma continental do Estado do Maranhāo. Dissertaçāo de mestrado. Universidade de São Paulo, Instituto Oceanográfico. 106 p.

PUGH, D. T. 1987. Tides, surges and mean sea-level. New York, John Wiley, 471p.

RAMMING, H. G. \& KOWALIK, Z. 1980. Numerical modelling of marine hydrodynamics, applications to dynamical physical processes. Amsterdam, Elsevier. 368p.

SCHWIDERSKI, E. 1980. On charting global ocean tides. Revs. Geophys. Space Phys. 18:243-268.

(Mamuscript received 08 April 1994; revised 02 December; accepted 24 May 1995) 